\title{
Integrating PAD Class to College English Reading Teaching
}

\author{
Yun Yue \\ Department of College English, Zhejiang Yuexiu University, Shaoxing, China \\ Email: miss0575@163.com
}

How to cite this paper: Yue, Y. (2021) Integrating PAD Class to College English Reading Teaching. Open Access Library Journal, 8: e7479.

https://doi.org/10.4236/oalib.1107479

Received: April 30, 2021

Accepted: June 6, 2021

Published: June 9, 2021

Copyright $\odot 2021$ by author(s) and Open Access Library Inc.

This work is licensed under the Creative Commons Attribution International License (CC BY 4.0).

http://creativecommons.org/licenses/by/4.0/ (c) $\underset{\mathrm{By}}{\text { (i) Open Access }}$

\begin{abstract}
Reading is an important way for people to obtain information. The improvement of reading ability is the key to English learning. In order to improve English reading teaching effectiveness, a new teaching mode called PAD (Presentation-Assimilation-Discussion) class is adopted. In this paper, the author focuses on the application of PAD class in college English reading instruction: reconstruction of teaching material, fostering analytical reading competence and formative assessment in college English reading context.
\end{abstract}

\section{Subject Areas}

Teaching and Learning Technologies

\section{Keywords}

English Reading Teaching, Effectiveness, PAD Class

\section{Introduction}

English reading is the main source of language input and accumulation, which is the basis of improving students' comprehensive use of language. Therefore, reading instruction has always been an important part of college English teaching. Many scholars in China have explored new approaches to the teaching of college English reading at the theoretical level. Professor Zhang Xuexin (2014) put forward the concept of PAD (Presentation-Assimilation-Discussion) class [1]. Many domestic scholars have carried out relevant research, the current research mainly includes the following aspects: 1) The introduction of PAD class research, such as Ma Luyan and Zhang Xuexin [2]. 2) Research on the application of PAD class in ESP teaching, such as Fu Yao, Zhu Jing [3] [4]. 3) Research on the application of PAD class in college English teaching for non-English majors. The abovementioned research has greatly enriched and promoted English teaching and 
promoted the implementation of the PAD class teaching. However, through literature research, we find that at present, an increasing number of scholars have done much research on the application of PAD class in English reading teaching [5] [6] [7] [8]. Deng Shuangquan (2017) and others have conducted research on the teaching of reading to non-English majors [9]. Effective college English reading teaching attracts more and more attentions among teachers.

\section{PAD Class}

PAD (Presentation-Assimilation-Discussion) class is a novel classroom teaching mode put forward by Professor of Zhang Xuexin from Fudan University. In 2014, after the first experiment of the undergraduate course in Fudan University, it quickly spread to the whole country. It has been widely practiced and recognized in various sections and many subject areas. It is simple and easy to use and the effect is remarkable, which has demonstrated the good versatility and the replicability. The theory of the PAD paradigm is mainly derived from social constructivism, which emphasizes the internalization of knowledge or psychological construction through social interaction. The prominent concepts are the zone of proximal development, mediation, and scaffolding. The learning process is considered to involve problem-solving and task completion through social interaction between the experts (teachers, excellent students) and novice (students). Teachers' presentation in the PAD class functions as "scaffolding" to provide a clear explanation and interpretation of new knowledge to develop the Zone of Proximal Development (ZPD) of individual learners. Additionally, scaffolding not only comes from teachers but also from peers and group members and students are expected to mediate the ZPD with each other in discussion and negotiation.

The division of classes combines the traditional wisdom of teaching and solving puzzles with the essence of Western cooperative learning based on discussion, it has formed a four-element teaching paradigm, which includes teacher' teaching, assimilation, peer discussion and answering. The core of PAD class is to split classroom teaching and learning into two parts. Teachers are in charge of teaching and answering questions, and students are in charge of learning and discussing, thus building a community of teachers and students with reasonable division of labor. By giving back part of the class time to the students, we can not only make the students become the master of learning, arouse their enthusiasm for study, but also let the teachers reduce the heavy mechanical work so as to have a good teaching effect, enhancing the sense of professional accomplishment of teachers [1].

\section{Analysis of the Present Situation of College English Reading Instruction}

\subsection{Too Much Emphasis on Vocabulary and Grammar Training}

Traditional English reading instruction focuses too much on vocabulary and grammar training. This kind of teaching method can not help students master English reading knowledge and information. Only by arousing the students' in- 
terest and enthusiasm in reading can the students take the initiative to participate in English reading and deepen their understanding of English knowledge. At present, college English teachers are not good at using modern diversified teaching methods, which results in the contradiction between theoretical learning and practical reading. Therefore, the reading teaching mode urgently needs to be reformed. Teachers give priority to teaching language knowledge, and students' exercises aim at consolidating knowledge.

\subsection{Monotonous Teaching Objectives}

In the current teaching process of college English reading, the teaching objectives have gradually shown a trend of unification, and many teaching objectives are unitary, as a result, the teaching content and practice are derailed, it is difficult to arouse the students' interest in learning, the students' English reading is limited to the textbook content, and the reading content outside class is not enough, so it is difficult to achieve good English reading teaching effect. At the same time, in the teaching of college English reading, too much attention is paid to the teaching of students' theoretical knowledge, while the training of students' oral expression ability is neglected. As a result, students can not read English materials correctly, the student lacks the independent study ability and the innovation ability. This type of teaching has been around for a very long time, and it's very difficult to change that in the short term [10].

\subsection{Lack of Scientific Assessment Mechanism}

Due to the lack of a sound assessment mechanism in English reading teaching, the timeliness of English reading teaching can not be brought into full play. In College English Reading Teaching, the traditional examination paper is still used to judge the students' English reading comprehension ability and whether they have the English reading knowledge. This kind of examination paper examination method has big limitation, the examination content is too fixed, completely takes the reading comprehension theory knowledge as the main point, the reading comprehension theory knowledge point is the content which the student needs to grasp emphatically, it is necessary to combine listening and speaking in the teaching of English reading. Reading and writing should be judged in a comprehensive way, and students' oral ability should be examined. Only when students have a good command of oral English can they carry out English reading activities, therefore, English reading teaching mainly focuses on cultivating students' practical knowledge. If we continue to use the traditional English examination mechanism, it is difficult to investigate the students' English reading, which makes the English examination lose its real effect.

\section{Application of PAD Class in College English Reading Instruction}

\subsection{Reconstruction of Teaching Materials}

If the content of teaching materials is organized in accordance with the idea of 
the PAD class, teaching will be more scientific, convenient and efficient. The traditional classroom overemphasizes "teaching", and the demarcation between "teaching" and "learning" is not clear enough, the two are mixed together. The core idea of PAD class is the balance between "teaching" and "learning", which requires a clear separation of the two. In the reading section, for example, each unit has two texts of the same subject and difficulty, text A for teaching, text B for learning. Lecture: the teacher explains text $\mathrm{A}$ and demonstrates the knowledge, strategies, methods and skills needed and involved in understanding the A text. Independent Study: students apply the strategies and methods demonstrated by their teachers to try to understand text B. In the process of independent study and thinking, students find and mark their own problems. Discussion: Through 3 - 4 person group discussion, the student solves the problem cooperatively in the communication, refines the common problem. PAD classes require students to listen to lectures, read books and complete regular assignments, then summarize what they feel most deeply, benefit most, and appreciate most in the learning process, called "My favorites". Also as to what they clearly understand, but others may have confused, they can challenge others, called "Test you". What you don't know or want to know, you should express it in the form of a question, and ask your classmates for help in the discussion. "Liangkaobang", as the condense and reflection of the learning experience in the stage of independent study, provides the high-quality material and the key support for the following discussion. In the group discussion, students not only share the results of learning, but also share the thinking process and learning strategies, learn from each other, learn how to learn, and then enhance the ability of self-study.

\subsection{Fostering Analytical Reading Competence}

The focus of reading instruction is not on grammar and vocabulary, which have separate sections. When the text involves difficult grammar, the teacher can simply explain the case, do not need to expand; when encountered new words, do not explain in details. Reading teaching should train analytical reading ability, that is, the core ability of logical analysis of sentence and text structure. At the sentence level, students should identify and label the key components of the sentence, such as the subject, predicate and the subordinate part of the compound sentence. At the paragraph level, students should identify and label topic sentences, extended sentences, concluding sentences and conjunctions, and infer and clarify the relationships between sentences. At the textual level, students should be taught to recognize conjunctions and find the logical relations of progression, causality and juxtaposition among paragraphs. Analytical reading requires logical reasoning to deconstruct the text with the help of grammatical rules, background knowledge, etc. in limited time. When the local details are not clear, by analyzing the logical relationship between word and word, sentence and sentence, paragraph and paragraph, we can grasp the structure of the whole text. Students learn the whole meaning and deep processing, not for individual words, emphasizing the overall, high-level, extended, integrated, derived, deduc- 
tive, integrated understanding. Proficiency in reading is essentially a skill that requires many principles, methods, and techniques, as well as a great deal of tacit knowledge that is difficult to articulate in language. Both the cultivation of skills and the acquirement of tacit knowledge require repeated practice and more practice on the basis of teacher's demonstration. The teacher explains through the text, shows the students how to read, the students then learn by imitating in their own independent reading process, gradually enhances the reading competence.

\subsubsection{Lecturing}

The teacher explains text A and demonstrates the reading method. To help students master the structure of a text and understand the logical structure between paragraphs, they can find out the connectives which indicate the logical relations in an interactive way and use the connectives. The teacher organizes students to carry on the study. After reading a passage, the teacher can ask the students to discuss the topic, the words and the structure of the passage. The teacher can also ask them to relate what they have read to their own lives, to what they have learned before, or to what they have discussed in class. Next, the teacher organizes the students to comment and analyze the reading, and the teacher comments on the best comments to help the students figure out what comments are valuable. These activities should be done in the classroom so that students can get timely feedback. Through demonstration, students can study carefully and independently. After the students understand the meaning and the theme of the article, the teacher should consolidate the students' understanding and mastery of the reading skills through a lot of practice. For example, in the above example, the author set up six questions before and after reading, these questions are related to understanding, application, analysis and evaluation, and so on.

\subsubsection{Independent Learning}

Students review the content of teacher's explanation, read text B independently, trying to use the method of teacher's demonstration and mark difficulties. According to the knowledge transfer, the internalization activities carried out after teacher's demonstration of text A. Reading is a necessary stage of "independent learning", which is of great significance. Only through reading can students gain more profound, comprehensive understanding of the text. In the process of independent reading, students can connect the new knowledge with the old knowledge. Teaching materials can not fully meet the needs of students, in order meet the diversified needs of students, it is necessary to recommend and provide relevant learning materials, including reference books, videos recommended by teachers. After the teacher's lecture, students review the content of the teacher's lecture, digest and absorb what they read, and combine what they have learned with their own experience. Reading is not enough, therefore students need to learn deeply, to take notes through reading. Students are supposed to extract key knowledge points, sort out the logical relationship between each knowledge 
point, students write the knowledge points by themselves [11].

\subsubsection{Discussion}

Students share and exchange ideas with other students. They discuss or debate a particular point in a group discussion. During the discussion, students can not only learn collaboratively, help each other, solve problems together, but also learn other students' reading strategies and discussion methods, so as to improve their reading skills and thinking ability. At this stage, the teacher, as a participant in the class discussion, should participate in the students' discussion. Such a teaching method not only enables students to have a better understanding of the reading text, but also shares the ideas and wisdom of all the participants in the class with the teachers and all the students. Learning is not only a student's individual construction activity, at the same time, it is also a cooperative construction process of student groups, which can not only enrich individual understanding, but also make knowledge reach the necessary consistency. Group discussion can not only help each other solve problems, but also let the students learn other students reading strategies, analysis and problem-solving strategies, therefore improve students' reading. Cooperative learning helps to carry out class discussion, effectively reduce reading anxiety, build up the confidence of reading study, and improve reading comprehension so as to achieve the goal of internalizing knowledge.

\subsubsection{Answering}

After group discussion, the students still have some problems that are difficult to solve, which can be put forward. Teachers focus on response and comment. The teacher answers questions and summarizes in class.

\subsection{Formative Assessment of Learning Effects}

PAD class based reading teaching is conducive to the development of formative assessment. It brings about the change of teaching and learning methods, and it will inevitably bring about the change of assessment methods. Generally speaking, the assessment emphasizes the process evaluation, increases the specific content of usual assessment, and disperses the assessment of learning effectiveness to the specific tasks of each teaching unit, which truly reflects the process evaluation. In addition, we pay more attention to the learning needs of different students (Zhang Xuexin, 2014). Students have a relatively fixed learning task in the after-school learning stage of each unit. One is "liang bang kao", that is, to effectively absorb the content taught by teachers, to put forward highlights, to test peers, and to ask for help; there are various forms of homework, and there is no unified standard answer. As long as you hand it in, you will get results. Teachers mainly give scores and evaluation according to the students' degree of completion, that is to say, this assessment method pays more attention to the students' learning process, and at the same time pays attention to the learning needs and personal characteristics of different students, so the assessment results 
are more scientific and objective, and avoids the phenomenon of neglecting the usual study and relying on the rush to get a high score before the examination.

To be specific, the formative assessment in English reading class is based on the following aspects. 1) Process evaluation. The students' learning activities are very important. It is the main part of teaching and learning, and evaluation in the process of learning can get better results. Accurate and effective data can also give teachers and students better process reference. It can also stimulate the initiative and enthusiasm of students more effectively. 2) Performance evaluation. More attention should be paid to students' use of what they have learned in class. The ability to complete learning tasks or solve practical problems is emphasized And the focus is on the sustainable development of students. Performance evaluation aims to observe and judge students' learning behavior, to make students more actively participate in classroom activities, and strive to improve thinking, interaction and collaboration to better understand and master knowledge. 3) Developmental evaluation. The PAD class mode reflects the students' personality. We should pay attention to the cultivation of students' quality and guide them to study independently and effectively and build their own knowledge structure. Developmental assessment can make learning behavior more effective [12].

\section{Conclusions}

Classroom is the most important place for teaching activities, and promoting classroom revolution is the only way to improve the teaching quality of higher education in the new era. It is necessary to transform traditional classroom into the modern classroom and carry out a systematic and profound reform in the teaching of university courses, constructing the teaching process supported by profound scientific theory. Scientific Teaching is especially important for language education, because language is the core cognitive function of human beings, involving a very wide range of brain regions and neural networks, and its complexity is far beyond the grasp of intuitive experience.

College English reading teaching based on PAD class is a novel and effective paradigm of teaching. On the one hand, students can transform their learning habits from passive to active. They set individualized goals for their learning. They are more willing to prepare in advance to ensure the effectiveness of the group discussion. At the same time, under the influence of peer pressure, it can encourage students to listen carefully in class. Besides, it develops students' autonomous learning habit after class, students are no longer simply deal with the teacher's assignment. If students can't solve the problem, they can ask the teacher for help, which makes the students closer to teachers.

On the other hand, it also puts forward higher requirements for teachers. Teachers must have rich knowledge, get familiar with the key and difficult points, especially the questions that students may ask. Therefore, teachers should constantly improve their teaching ability and professional level. For example, 
teachers should know how to organize the classroom teaching, how to allocate the discussion time reasonably, and improve the efficiency of group teaching.

Although some positive findings are proved, some limitations are also acknowledged. Firstly, there are limitations about scale of participations, which are restricted to only two classes of second-year college students. Therefore, the result of this study is far from conclusive. Secondly, PAD class based English reading teaching helps students a lot, still some aspects are ignored during the experiment. Future studies on larger scale students group or more teachers in more classes are recommended in order to bring about more evidence on the benefits of the new teaching mode.

\section{Conflicts of Interest}

The author declares no conflicts of interest regarding the publication of this paper.

\section{References}

[1] Zhang, X.X. (2014) PAD Class: A New Exploration of College Classroom Teaching Reform . Fudan University Education Forum, 5, 5-10.

[2] Ma, L.Y. and Zhang, X.X. (2020) The Characteristics of "Lecture" in the Mode of PAD Class Teaching. Heilongjiang Education (Theory and Practice), 10, 75-76.

[3] Fu, Y. (2017) Analysis of Business English Classroom Teaching in Higher Vocational Colleges Based on PAD Class. Modern Communication, 9, 162.

[4] Zhu, J. (2017) Research on the Reform of Business English Teaching Mode Based on PAD Class. Technology Wind, 2, 48.

[5] Zhou, L. (2016) Research on the Application of PAD Class in College English Reading Teaching. Education Observation, 5, 92-93.

[6] Shi, L.P. (2018) Exploration and Practice of PAD Class in College English Reading Teaching. Comparative Study of Cultural Innovation, 2, 119-120.

[7] Zhang, L.Y. (2018) Research on the Application of PAD Class in English Reading Teaching. New Oriental English (Chinese and English Version), 1, 46-47.

[8] Liang, S.G. and Li, J. (2019) An Empirical Study on the Effectiveness of PAD Class Teaching Mode in College English Reading Teaching. Journal of Chuzhou Polytechnic, 18, 64-67.

[9] Deng, S.Q. (2017) Classroom: A New Exploration of College Public English Reading Teaching. Campus English, 10, 34.

[10] Xiao, H. and Chen, D. (2018) Research on College English Reading Teaching Mode under Flipped Classroom Mode. Foreign Languages, 34, 147-154.

[11] Ma, L.Y. and Zhang, X.X. (2021) Research on the "Independent Learning" in PAD Class. Jiangsu Science and Technology Information, 38, 77-80.

[12] Xu, X.H., Zhang, X. and Li, G.Y. (2018) Research on the Construction of Teaching Evaluation System Based on Effective Learning. Industry and Technology Forum, 19, 219-220. 